\title{
Enzymatic Systems Involved in D-limonene Biooxidation
}

\author{
Pilar Menéndez ${ }^{1}$ Carlos García ${ }^{1}$; Paula Rodríguez ${ }^{1}$; Patrick Moyna ${ }^{2 *}$ and Horacio \\ Heinzen ${ }^{1}$ \\ ${ }^{1}$ Cátedra de Farmacognosia y Productos Naturales; Facultad de Química; Avda. General Flores 2124; C.C. 1157; \\ Montevideo, Uruguay; menendez@bilbo.edu.uy. ${ }^{2}$ Instituto de Biotecnologia; Universidade de Caxias do Sul; CEP \\ 95070-560; Caxiasdo Sul-RS, Brazil; pmoyna@ucs.tche.br
}

\begin{abstract}
The biooxidation of limonene by an Aspergillus strain resulted in the production of perillyl alcohol and short chain fatty acids. Addition of ketoconazole, a known inhibitor of cytochrome P450 oxydase, eliminated the production of free acids, but did not affect biotransformation to perillyl alcohol.
\end{abstract}

Key words: Limonene, biotransformation, perillyl alcohol, cytochrome oxydase, inhibitors

\section{INTRODUCTION}

D-limonene (4-isopropenyl-1-methylcyclo hexene) is one of the most widely distributed monoterpenes and is biosynthesised by more than 300 different plants (Burdock, 1995). (4 R) - (+) - limonene (Fig. 1, 1) is the most frequent isomer, being the main constituent of citric essential oils, where it represents between 70 and 96\% (Braddock \& Cadwallader, 1995; Bruneton, 1995; Evans, 1989). In uruguayan citric essential oils, it represents $70 \%$ of the lemon oils and $93 \%$ of the sweet orange oils (Dellacassa et al., 1991). Limonene does not contribute to the aroma, so it is usually separated from the oils by deterpenation processes. It is therefore abundant and low priced, and is frequently used as substrate for the chemical synthesis of nature-identical odorants (Braddock \& Cadwallader, 1995; Evans, 1989; Nonino, 1997; van Dyk et al., 1998).

The biotransformation of (+)-limonene using different microorganisms (bacteria, yeasts and fungi) has been extensively studied, searching for ways of producing compounds of higher value. Different oxygenated terpenes have been reported as biosynthetic products ( $\alpha$-terpineol, perillyl aldehyde, carveol, carvone, piperitone, etc.) (Abraham et al., 1986; Bowen, 1975; Braddock \& Cadwallader, 1995; Kraidman et al., 1969; Murdock \& Allen, 1970; Murkherjee et al., 1973; Noma et al., 1992; Rama Devi \& Bhattacharyya, 1977; Tan \& Day, 1998; van Rensburg et al., 1997).

Using an Aspergillus niger strain isolated from sweet orange peels we observed the production of mixtures of free short-chain organic acids and perillyl alcohol (Fig. 1, 2). To study the possible enzymatic systems involved in these oxidations, we added ketoconazole, which is known to inhibit cytochrome P450 oxydase (Karp et al., 1990) to the growth media.

\footnotetext{
* Author for correspondence
} 


\section{MATERIALS AND METHODS}

\section{Reagents}

Analytical grade solvents (Merck, Darmstadt, Germany) were distilled prior to use. Pure dlimonene was from Fluka (Basel, Switzerland). Ketoconazole was from Roemmers (Montevideo, Uruguay). Pure standards were from Aldrich (Milwaukee, USA).

\section{Gas chromatography}

A Shimadzu GC14B gas chromatograph (Kyoto, Japan) equipped with FID and EZChrom integration software for data processing was used. Fused silica capillary columns $(30 \mathrm{~m} \times 0.32 \mathrm{~mm}$ i.d.) with bonded SE52 $(0.40-0.45 \mu \mathrm{m}$ thickness $)$ and Carbowax 20M (0.25 $\mu \mathrm{m}$ thickness) were used. Temperature programme: $60^{\circ} \mathrm{C}, 8$ minutes; $60^{\circ}-210^{\circ} \mathrm{C}$ at $3^{\circ} \mathrm{C} / \mathrm{min}$; injector temperature: $240^{\circ} \mathrm{C}$; detector temperature: $250^{\circ} \mathrm{C}$. Carrier gas: $\mathrm{H}_{2}$ at $0.50 \mathrm{~kg} / \mathrm{cm}^{2}$; injection system: split, ratio 1:100.

GC-MS were completed with a Shimadzu QP 1100-EX in the same conditions, using $\mathrm{He}$ as carrier gas. The identifications were completed by comparison of retention times against standards and Kovats indexes, and by MS using a Wiley spectra library.

\section{Microorganism and culture}

An A. niger strain was isolated from sweet orange peels and kept at the Collection of the Cátedra de Microbiología (Facultad de Química, Montevideo, URUGUAY) as BFQU 68. The strain was grown in PDA slants (DIFCO, Detroit, USA) at $28^{\circ} \mathrm{C}$ until sporulation, and then kept at $4^{\circ} \mathrm{C}$. Growth Media was TSB (Sigma, St. Louis, USA).

The innoculum was a spore suspension adequate for a final concentration of $10^{5}$ spores $/ \mathrm{mL}$ in the growth media, prepared from a fresh culture of 72 hrs. growth.

The growth experiments were carried out at room temperature $\left(28^{\circ} \mathrm{C}\right)$ in a Sanyo IOC400.XX2.C orbital shaker (Tokyo, Japan) at 100 r.p.m.

\section{Trial runs}

Experiments with inhibitor (Trial 1) and without inhibitor (Trial 2) were carried out in quintuplicate.
Trial 1 (without inhibitor). Limonene was added after 48 hrs. incubation such as to attain a final concentration of $0.5 \%$ in the growth media. Samples were taken for analysis after reaction times of 5, 6, 7 and 9 days.

Trial 2 (with inhibitor). Ketoconazole was added after 48 hrs. incubation to attain a final $50 \mu \mathrm{M}$ (Karp et al., 1990) concentration in the growth media. Limonene was added 15 minutes after the addition of the inhibitor, to obtain the same final concentration as in Trial 1. Samples were taken after 7 days reaction time. Other conditions are unchanged.

Blanks using $A$. niger and growth media without limonene or ketoconazole, and adding limonene to growth media (without innoculum or ketoconazole) were carried out simultaneously.

\section{Extraction}

After the selected reaction times the media and mycelia were filtered and extracted with EtOAc. The organic extract was concentrated by rotary evaporation under vacuum at room temperature.

\section{RESULTS AND DISCUSSION}

Gas chromatography indicated the presence of 5 main components after comparison of the results from Trial 1 and blank experiments. The four biotransformation products are shown in Table 1.

Table 1- Percentage of biotransformation products. Mean of five runs.

\begin{tabular}{lcc}
\hline Bioproduct & Trial 1 & Trial 2 \\
\hline Perillyl alcohol & 28.5 & 100.0 \\
Propanoic acid & 11.0 & 0 \\
Isobutyric acid & 33.3 & 0 \\
Isopentanoic acid & 27.2 & 0 \\
\hline
\end{tabular}

Propanoic, isobutyric and isopentanoic acids (Dhavalikar \& Bhattacharyya, 1966; Dhavalikar et al., 1966), perillyl alcohol (van der Werf et al., 1999) and 2,5-dimethylpyrazine (Fig. 1, 3) are present together with residual limonene (Fig. 2). When ketoconazole was added (Trial 2) the only biotransformation products present were perillyl alcohol and 2,5-dimethylpyrazine (3).

The production of 2,5-dimethylpyrazine cannot be explained by any simple biotransformation of the 
structure of limonene, but it is clearly absent in both blanks (Fig. 4), so its formation seems to be directly related to the presence of the terpene.

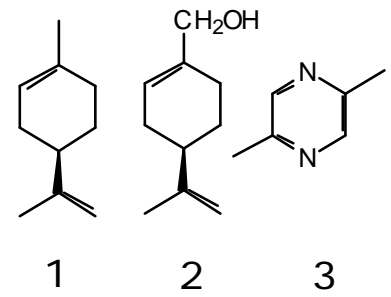

Figure 1 - 1. d-limonene, 2. Perillyl alcohol,

\section{2,5-dimethylpirazine.}

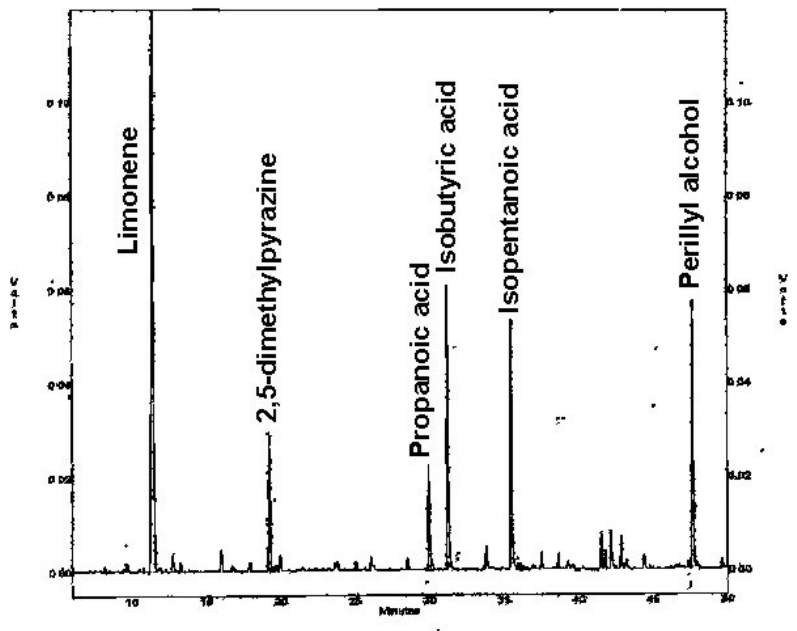

Figure 2 - Gas chromatography corresponding to trial 1.

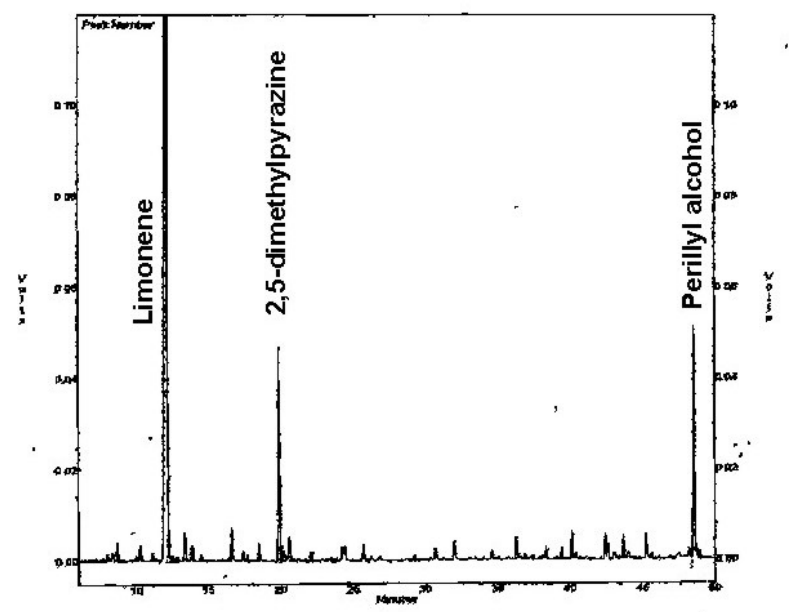

Figure 3 - Gas chromatography corresponding to trial 2.
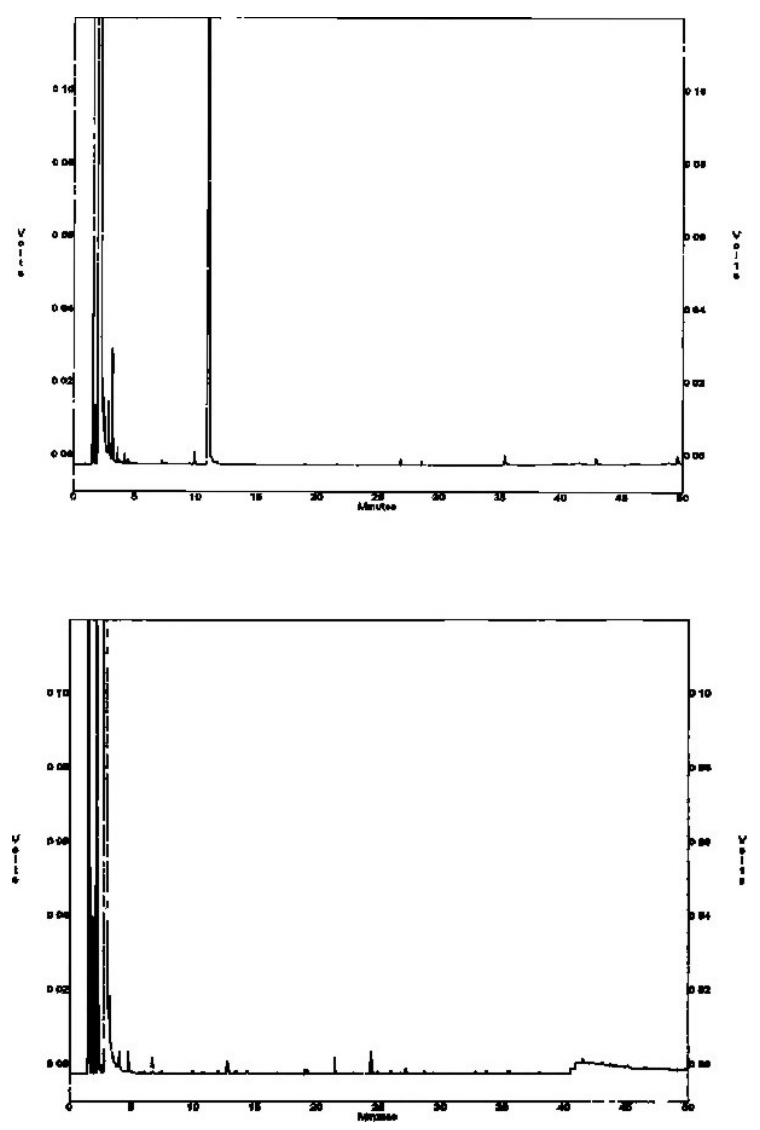

Figure 4 - Gas chromatography corresponding to blank experiments.

Ketoconazole is a inhibitor of cytochrome P450 oxydase (Karp et al.), and when present in the growth media clearly inhibits the synthesis of short chain free fatty acids (Figs. 2 and 3). There is no inhibition of the oxidation of limonene to perillyl alcohol, so this transformation seems to proceed through a different oxidation mechanism.

\section{Conclusions}

The biotransformation of d-limonene to the free short-chain fatty acids by $A$. niger and the inhibition of their biosynthesis by ketoconazole implies the participation of a form of cytochrome P450 oxydase in the reaction. This does not apply to perillyl alcohol. The use of a cytochrome P450 oxydase inhibitors in similar biotransformations could be a method of orienting the resulting reactions to specific products.

\section{ACKNOWLEDGEMENTS}

The authors are grateful to CSIC (Universidad de la República, Montevideo, URUGUAY; pre- 
Industrial Project 190) and to PEDECIBAQuímica (Montevideo, URUGUAY) for financial support which made this work possible; to Q.F. L. Ferrando and Bach. G.González for technical help.

\section{RESUMO}

A biooxidação do limoneno por uma linhagem de Aspergillus resulta na produção de álcool perílico e ácidos graxos de cadeia curta. A adição de quetoconazol, um conhecido inibidor da citocromo P450 oxidase, elimina a produção de ácidos graxos livres, mas não afeta a biotransformação a álcool perilhílico.

\section{REFERENCES}

Abraham, W. R.; Stumpf, B. and Kieslich, K. (1986), Microbial transformations of terpenoids with 1-pmenthene skeleton. Appl.Microbiol Biotechnol., 24, 24-30.

Bowen, E. R. (1975), Potential by-products from microbial transformation of Dlimonene. Proc. Flo. State Hort. Sci., 88, 304-308.

Braddock, R. J. and Cadwallader, K. R. (1995), Bioconversion of citrus d-limonene. In - Rouseff, R. L. and Leahy, M. M. (Eds.), Fruit Flavors: Biogenesis, Characterization and Authentication, ACS Symp. Series N596. Washington, DC. pp. 142-148.

Bruneton, J. (1995), Pharmacognosy, Phytochemistry, Medicinal Plants. Intercept, London. pp. 448-449.

Burdock, G.A. (1995), Fenaroli's Handbook of Flavour Ingredients. CRC Press, Boca Raton. pp. 107-109.

Dellacassa, E.; Rossini, C.; Moyna, P.; Stagno D'Alcontres, I.; Mondello, L. and Dugo, G. (1991), Gli olii essenziali dell'Uruguay. Nota II. Essenz Der. Agrumari, 61, 291-304.

Dhavalikar, R. S. and Bhattacharyya, P. K. (1966), Microbiological Transformations of Terpenes. Part VIII. Fermentation of limonene by a soil Pseudomonad. Indian J Biochem., 3, 144-157.

Dhavalikar, R. S.; Rangachari, P. N. and Bhattacharyya, P. K. (1966), Microbiological Transformations of Terpenes Part IX. Pathways of degradation of limonene in a soil Pseudomonad. Indian J Biochem., 3, 158-163.

Evans, W. C. (1989), Farmacognosia Trease y Evans. Interamericana McGraw-Hill, México. pp. 480-483.
Karp. F.; Mihaliak, C.; Harris, J. and Croteau, R. (1990), Monoterpene Biosynthesis: Specificity of the Hidroxylations of (-)-limonene by Enzyme Preparations from Peppermint (Mentha piperita), Spearmint (Mentha spicata), and Perilla (Perilla frutescens) Leaves. Arch. Biochem. Biophys., 276, 219-226.

Kraidman, G.; Mukherjee, B. B. and Hill, I. D. (1969), Conversion of Dlimonene into an optically active isomer of $\alpha$-terpineol by a Cladosporium species. Bacteriol.Proc.,69, 63-67.

Murdock, D. I. and Allen, W. E. (1970), Bacteriological contamination of some citrus oils during processing. J. Food Sci., 35, 652-656.

Murkherjee, B. B.; Kraidman, G. and Hill, I. D. (1973), Synthesis of glycols by microbial transformation of some monocyclic terpenes. Appl. Microbiol., 25, 447-453.

Noma, Y.; Yamasaki, S. and Asakawa, Y. (1992), Biotransformation of limonene and related compounds by Aspergillus cellulosae. Phytochemistry, 31, 2725-2727.

Nonino, E. A. (1997), Where is the citrus industry going? Perf. Flavour., 22, 53-58.

Rama Devi, J. R. and Bhattacharyya, P. K. (1977), Microbiological transformations of terpenes. Part XXIII. Fermentation of geraniol, nerol and limonene by a soil Pseudomonad, P. incognita. Indian $J$. Biochem. Biophys., 14, 288-291.

Tan, Q. and Day, D. F. (1998), Bioconversion of limonene to $\alpha$-terpineol by immobilized Penicillium digitatum. Appl. Microbiol. Biotechnol., 49, 96-101.

van der Werf, M. J.; Swarts, H. K. and de Bont, J. (1999), Rhodococcus erythropolis DCL14 contains a novel degradation pathway for limonene. Appl. Env. Microbiol., 65, 2092-2102

van Dyk, M. S.; van Rensburg, E. and Moleleki, N. (1998), Hydroxylation of (+) limonene, (-) $\alpha$-pinene and (-) $\beta$-pinene by a Hormonema sp.. Biotech. Letts., 20, 431-436.

van Rensburg, E.; Moleleki, N.; van der Walt, J. P.; Botes, P. J. and van Dyk, M. S. (1997), Biotransformation of (+) limonene and (-) piperitone by yeasts and yeast-like fungi. Biotech. Letts., 19, 779-782.

Received: September 29,2000; Revised: March 06, 2001; Accepted: June 25, 2001. 